\title{
Motivations and Self-Perceived Career Prospects of Undergraduate Sociology Students
}

\author{
Alexandra Valéria Sándor \\ Eötvös Loránd University, Faculty of Social Sciences, Doctoral School of Sociology
}

\section{Abstract}

Sociology undoubtedly plays an important role in the world of sciences, as it provides an opportunity to examine the society in which we live and our social relationships using widely accepted means with real scientific value. As Giddings has noted, 'sociology tells us how to become what we want to be' (Giddings, 2011). However, discussions of the social sciences can be controversial, as they are sometimes perceived as 'inferior' to natural sciences. To alleviate this discrepancy, it is essential to supply professionals with useful knowledge in the field of sociology, understand their motivations and ensure the best career prospects for them. In this pilot study, 18 sociology B.A. students answered seven open-ended questions in the form of a short essay regarding their motivations in terms of faculty choices, initial expectations and the fulfilment thereof, their aims in the study of sociology, preferred areas of employment, willingness to undergo further training, five-year plans and their opinions about the prospects of newly graduated sociologists in Hungary compared to graduates from other areas in terms of the usefulness of knowledge gained, perceptions of their professions and earning opportunities. According to the results of this study, the future plans of the participants were very different, but all of them believe that an undergraduate sociology degree provides extensive knowledge about the functioning of society and has helped them to form attitudes that they consider to be extremely valuable on the labour market.

Keywords: career prospects, education, motivations, sociology, undergraduate programme.

\section{Introduction}

Sociology as a science is essential for understanding the functioning of society. By definition, 'sociology is a social science that studies human societies, their interactions, and the processes that preserve and change them. It does this by examining the dynamics of constituent parts of societies such as institutions, communities, populations, and gender, racial, or age groups. Sociology also studies social status or stratification, social movements, and social change, as well as societal disorder in the form of crime, deviance, and revolution' (Form \& Faris, 2020). Thus, one could make the claim that sociology training plays an important role in social development and that sociology courses aim to train professionals who are able to understand and analyse social processes, thus contributing to the development of society.

The short description of the sociology BA programme at Eötvös Loránd University in Budapest, Hungary includes the statement that 'successful graduates of the program should have a solid grasp of the concepts and principles of sociology and have mastered (at the 
appropriate level) its methods, and they should be able to identify and interpret social problems meaningfully' (ELTE, 2020).

However, the role of sociology - and the role of the social sciences overall - among the range of sciences still may not be as clear as that of the natural sciences or engineering. As Durkheim states, according to his positivist view of science that has greatly influenced the field of sociology, there are objective facts about the social world that can be expressed in statistics, and these facts are not influenced by the personal beliefs of the researcher (Durkheim, 1897). On the other hand, social action theorists argue that the social world is socially constructed itself, and, from a postmodernist point of view, the social world cannot be observed directly, only through language, which raises the question of different possible meanings (Thompson, 2017). Ironically, the discipline that deals with the nature and operations of science is a branch of sociology: the sociology of science.

Sociologists - together with representatives of other disciplines - take on the task of helping us to better understand the world around us. During their training, it is essential to supply them with motivation and ensure the best career prospects for them. The present pilot study aims to provide a snapshot of the motivations and self-perceived career prospects of undergraduate sociology students, hypothesising that they will have experienced misconceptions related to overall societal perceptions of sociology, identifying potential patterns in their motivations and career prospects and eventually observing whether these patterns are worthy of further examination on a larger scale.

\section{Methodology}

To assess the motivations and self-perceived career prospects of undergraduate sociology students, 19 participants - the entirety of an elective course-unit at Eötvös Loránd University in the second semester of the academic year 2019-2020 - were asked to write an essay of at least three pages responding to the prompt 'What are my prospects as a sociology student?' that answers seven open-ended questions.

The questions were as follows:

- Why did you choose undergraduate training in sociology? (What factors played a role in the choice?)

- What were your ideas and expectations in the beginning?

- Have your ideas been fulfilled, and have your expectations been met? (In what ways have they or have not?)

- What primary goal did you hope to achieve with this training at the time of application, and did this goal change during your training? (If it has changed, can you tell when and why exactly?)

- What field would you like to work in, and do you have any plans for further study?

- When are you expected to graduate? Where do you see yourself in five years?

- What do you think the prospects of newly graduated sociologists are today in Hungary, and how different do you think these are compared to those of students graduating from other programmes (regarding the usefulness of knowledge gained, perceptions of the profession, 
earning opportunities or anything else that comes to your mind compared to any other major or discipline)?

The participants were encouraged to make open and honest statements about their personal thoughts and feelings. Ultimately, 18 students returned their essays before the deadline for anonymous data processing. All of the participants were second- or third-year sociology BA students in full-time training at the time of data collection that took place between 6 and 11 May 2020.

\section{Analysis}

The sample of 18 sociology students consisted of 13 women (72.2\%) and five men (27.8\%). 10 of them were second-year students (55.6\%) and eight were third-year students (44.4\%) between the ages of 19 and 28 .

In response to the first question, 'Why did you choose undergraduate training in sociology?', nine participants $(50 \%)$ answered that they had been interested in history in secondary school and thus became interested in the functioning of society. All participants (100\%) mentioned that they would like to gain a deeper understanding of the world around them. 'For me, it's a personal mission to understand people and myself, but I don't like the individualist approach of psychology', said one of the undergraduate students. However, three participants wrote that their first choice during application was a psychology BA, but they did not manage to fulfil the requirements; they realised later that this was 'a lucky incident', as they find sociology to be a 'more comprehensive' discipline. The effects of media were also apparent in the choices of the students. 'I've heard sociologists talk about different social issues on the radio many times and found it interesting. I thought I was going to learn something similar', one wrote. All of the participants $(100 \%)$ mentioned some kind of uncertainty regarding their profession at the time of application, but the level of this uncertainty was highly variable. 'I went to a high school that provided many opportunities for social and community involvement. We organised camps for children in the summer and during the year in a completely voluntary way', explained one participant who sees themself 'as a community organiser' in the future.

This level of uncertainty was observed to be so high that it was difficult for some students to even conceptualise what they would like to study or do with their lives. 'Why should I know that at the age of 18?', asked one. The diversity of sociology was included among the primary motivations for study. 'Social science involves almost all of the sciences, so I saw an opportunity in it that even if I didn't get a job as a sociologist after graduation, it still provides a basic intelligence that I'll be able to adapt more easily, even to a job', said a participant. 'I wanted a degree that could make pretty much anything out of me', stated another. In some cases, current social issues motivated these young adults to choose sociology as their major: 'I wanted to understand what migration is, I wanted to understand why we communicate about it the way we communicate about it, I wanted to understand the emotions going on in people, what they were afraid of, I wanted to understand hatred because I thought there is no such thing as hate from the gut'. All of the students $(100 \%)$ declared that they chose a sociology BA because they felt that they could gain comprehensive knowledge from it, which could be applied in many areas: 'I read the training programme descriptions, and I sorted based on what knowledge I could gain. In the end, I chose sociology because I felt the knowledge I could gain in this major was the most comprehensive'. 
To the second and third questions, 'What were your ideas and expectations in the beginning?', and 'Have your ideas been fulfilled, and have your expectations been met? (In what way have they or have not?)', all participants (100\%) answered that they thought it was important to obtain a degree both because of personal development and because of its value on the labour market. Additionally, the applicability of knowledge was important to students. 'I expected to learn new and interesting things that I could then use in my daily life and that would make me understand a little better the people around me and how things work. At 90 per cent of the time, I learn things that I find very interesting, and I feel like I've managed to find the major that truly suits me best', shared a participant. The well-known difficulties of first-generation university students were also conveyed. 'I had no idea what to expect. I am the first in the family to go to university so my parents couldn't really help me', pointed out one student, who 'didn't expect how close sociology is to many other sciences' and was excited to study 'philosophy, psychology, social psychology [and] anthropology', admitting that their goals 'actually came about after the admission'.

Students emphasised the importance of sociology by expressing the fact that sociological knowledge can be implemented in daily life situations easily. 'My expectation that I wanted to understand the world around us has already been fulfilled. Very often in ordinary discourses, I notice the return of acquired thoughts in a given context. So not only [has] my knowledge expanded, but my way of thinking also became much more causal, more complex, more actual', wrote one student. On the other hand, more than half of the participants $(61.1 \%)$ observed that 'the training programme is especially characterised by reading the literature, too much of it'. The theoretical side of sociology caused one to remark: 'I envisioned the training completely differently. I imagined that there would be a lot more hands-on education at the university than lectures. In my vision, the training consisted of a lot of fieldwork to experience as much as possible, to increase our practical knowledge greatly'. Almost all of the participants $(94.4 \%)$ objected to the dominance of theoretical subjects in the programme ('I got a little too much of Marx, Durkheim and Weber'). Meanwhile, they emphasised how important they consider the various seminars and projects to be ('within the framework of our 15-credit project class, in which my team researched solidarity between the homeless, I realised that would like to work in an atmosphere after graduation in which I have the opportunity to add something to the social sciences'). However, the amount of educational materials related to the past was criticised by several participants: 'I was hoping that by the end of the course, there would be more contemporary issues as we live in the present'. It was also noted by one sociology student that 'if the goal is to educate thinking young people who also dare to express their different opinions, I think small groups of five to 10 would be the most ideal for this'.

Among the popular expectations expressed was the intention to meet and network with likeminded people. 'I wanted to make friends and connections, experience a bit of the university student life', wrote one participant. On the other hand, having a job made it difficult for several students to fulfil this expectation: 'I had difficulty establishing the right network of contacts, without which I did not have access to enough information. Thus, one quickly realises how much social capital matters'. Ultimately, all of the participants (100\%) claimed that the sociology BA programme fulfilled their expectations at least 'partly'. 'Miraculously, the training exceeded my expectations. I soon fell in love with it and learned a lot about how the world works. Even if not completely, I could still immerse myself in psychology and social psychology as well', indicated one student whose first choice of degree programme would have been a psychology BA. 
The fourth question, 'What primary goal did you hope to achieve with this training at the time of application, and did this goal change during your training? (If it has changed, can you tell when and why exactly?)', brought significant differences between students to the surface. 'My goal was to be able to understand and help as many people with difficult fates as possible. Perhaps a solution can be found to the question of how the problems of the Roma minority could be solved in the poorer regions of Hungary (Heves, Borsod, Nógrád, Szabolcs), and this goal has remained the same since', stated a participant who 'grew up in a small village where the proportion of Roma people is 65\%'. The goal of providing help was mentioned by others as well. 'For me, the primary goal is to deal with people: my work should have an impact on people's lives - if not personally, then indirectly. It also means to help people effectively', said another undergraduate sociology student. In some cases, students had initially formulated a concrete life goal: 'with my sociology training, my main goal was to get a basic education that would start me in life and help me realise what I wanted to be. I definitely thank the latter for the course, because before I came here, I had only a stray idea that I would like to hold training and courses for social sensitisation in the future'.

Other participants expressed completely different goals. For example: 'My goal when I applied for this training was to get a degree. It may sound a bit harsh now, but I didn't have a sublime goal or aspiration like social improvement. It was more of a rational decision'. However, some students with an initial goal such as this eventually became committed to sociology. As one noted, 'My goal with the training, in the beginning, was only to get a degree. This has changed to the extent that I no longer just want to get through, just avoiding the reclassification to a fee-paying student, but I want to complete all subjects as well as possible'. The uncertainty of professional choices also affected personal goals in some cases: 'I wanted to gain time to figure out what I was going to do in life. It worked out to some extent, as I had the opportunity to try myself in a job that requires a sociological vision in the business sector and helps people'. This student indicated that they would be glad to continue their job after graduation.

In certain cases, participants' goals changed within the field of sociology. 'For two semesters, my goal was to be able to study criminology and then go into that master's program as well. This goal changed when I saw the need to learn all kinds of laws and regulations. Then, I decided that I'm more interested in the organisational sociology specialisation', one participant mentioned. In contrast, some participants' ultimate goals moved beyond the framework of sociology: 'After the end of the second semester, it became clear to me what I would be interested in, and unfortunately, it was not this major. Since I was almost halfway through, I decided not to stop, finish it, start another undergraduate course and then go for a master's degree. I think the sociology BA is useful in all respects, as it provides an insight into getting to know the world around us, so it can provide a good foundation'.

To the fifth question, 'What field would you like to work in, and do you have any plans for further study?', half of the participants (50\%) mentioned that they would like to pursue master's-level studies in fields such as sociology, survey statistics, social policy, human ecology, community and civil development, human resources and design theory. 'I can't finish my studies by completing a sociology BA', explained one. Two students $(11.1 \%)$ indicated that they would like to pursue another bachelor's degree (in psychology and in communication and media studies), one (5.6\%) stated that they were considering a postgraduate specialist training course (possibly in human resources) and another (5.6\%) mentioned a planned gap year after graduation. Three participants (16.7\%) plan to obtain a PhD, two of these $(11.1 \%)$ in sociology and one in history (5.6\%). All participants (100\%) hope to use their knowledge 
of sociology in the labour market. Two (11.1\%) indicated that they were considering going abroad at some point to gain more experience. Regarding the field of work, ambitions of becoming a statistical researcher, policymaker or headhunter as well as 'working in the public sector', 'working for a civil organisation' and 'working for an appealing company' emerged. Working as a market researcher was considered attractive by two students (11.1\%). 'I don't want to work for anyone else at all unless I get something in addition to financial gain that can be valuable in the long run', a student pointed out. 'Unfortunately, the public sector can only be accessed through politics for a dedicated social politician who wants social change. It would be foolish to deny this. Anyone who wants to work as a social politician in public or municipal administration will ultimately be appointed by a politician, so social policy is not independent of ideology, either; ages and parties influence job opportunities', explained another participant.

To the sixth question, 'When are you expected to graduate? Where do you see yourself in five years?', eight students (44.4\%) answered that they were to graduate in a few months, nine $(50 \%)$ in the next year and one (5.6\%) two years later due to uncompleted courses. 'In five years, I want to be a person who feels responsible for society, actively intervenes in social processes and uses my knowledge of sociology to help humanity at my best', stated a participant. 'If all goes well, I'll graduate with a master's degree in human resources and work for a bounty hunter company, and maybe I'll learn something next to it that I can utilise later, saving money to start my own business and then a book publishing company', shared another. 'I would really like to join an NGO that meets my values. I haven't found the right one for me yet, but I'm primarily interested in the organisations that deal with the protection of the environment and the protection and support of the disadvantaged people', said a third participant. Not every participant's plans were clear. As one participant stated: 'To the question of where and how I will see myself in five years, I can't answer. I can't even imagine where this whole thing is going to go, but hopefully, I'll hold on to things and activities that are important and fun, like volunteering, creation and learning'. On the other hand, some participants were already on track to fulfil their five-year plans: 'In five years, I hope to be able to settle somewhere and earn enough to make a good living out of it. Incidentally, I have been just hired for an internship for data cleansing and machine learning'. Aspects of private life also emerged, as this answer demonstrates: 'I hope there will be someone on my side with whom I can share my life'. One student who pursued a political career wrote: 'If I burn out, I would like to set up either a social enterprise or a self-sustaining eco-farm in a village in a disadvantaged region to support local people and the community'.

To the last question, 'What do you think the prospects of newly graduated sociologists are today in Hungary, and how different do you think these are compared to those of students graduating from other programmes?', one student wrote that they are often asked 'What is sociology good for?' by others. 'The public judgment on sociology, I think, is rather negative, but not primarily because it would be less useful or relevant than other disciplines, but because the vast majority of people don't even know exactly what it means to study sociology or to be a sociologist', according to the observations of one participant. 'I had an acquaintance who, when they heard I was going to study sociology, said it was as useful as an underwater basket weaving course', complained another. 'I don't think that, as newly graduated sociologists, we would have very good prospects nowadays in Hungary, although I feel that there is a great need for sociologists, especially in the midst of emerging crises such as global warming and the refugee crisis', pointed out a third student. 'There are a thousand kinds of 
sociologists. It is a very big profession', warned the fourth, 'with several specialisations. It can be relatively easier to get a job [in some], and with others, it's harder, although I believe (maybe naively) that if someone is outstandingly good at something and can really put themselves out there, they can get a job anyway'. 'Today's Hungarian society and the labour market don't reward or value social scientists so much. But there is a market sector that absorbs those who are proficient in statistics, data visualisation and data analytics', mentioned another participant. Six students (33.3\%) referred to the importance of the reputation of the university. 'ELTE [Eötvös Loránd University] has the highest prestige in Hungary. The degrees obtained here are thoroughly acknowledged', one declared.

When comparing sociology to other majors, all participants (100\%) agreed that sociology is equally as important as any other discipline and that the undergraduate sociology programme provides useful knowledge. 'Basically, I think that [...] very few majors will mark a sure path to take [upon completion]', highlighted one. '[N]ew graduates need to realise that having a paper in their hands is just a springboard, but there is no guarantee that the employers will grab them with both hands in the job market, not if they are a sociologist nor if they graduated as an engineer', another student warned.

\section{Conclusion}

Despite the small sample size and nature of this research as a pilot study, it is able to provide a credible picture of the motivations and career prospects of undergraduate students in sociology as well as to draw attention to the misconceptions surrounding sociology and sociology training. The results of the essay analysis support the hypotheses that undergraduate sociology students experience misconceptions related to the overall societal perceptions of sociology and help to identify patterns in their motivations and career prospects. The observed patterns are definitely worthy of further examination using a larger sample of undergraduate sociology students.

\section{Acknowledgements}

The author would like to thank Eötvös Loránd University, Faculty of Social Sciences, Doctoral School of Sociology for the intellectual background and give special thanks to supervisor Dr György Csepeli, professor emeritus and head of the Interdisciplinary Social Research doctoral programme.

\section{References}

[1] Durkheim, E. (1952). Suicide: A Study in Sociology. Routledge.

[2] Eötvös Loránd University [ELTE]. Description of the Sociology BA Programme. Retrieved October 2, 2020, from https://www.elte.hu/en/sociology-ba

[3] Form, W., Faris R. E. L. (2020, May 6). Sociology. Encyclopædia Britannica. Retrieved October 2, 2020, from https://www.britannica.com/topic/sociology

[4] Thompson, K. (2017, January 15). Is Sociology a Science? Retrieved October 2, 2020, from https://revisesociology.com/2017/01/15/is-sociology-a-science/ 